\title{
DYNAMIC ANALYSIS OF RC REGULAR AND IRREGULAR STRUCTURES USING TIME HISTORY METHOD
}

\author{
Malavika Manilal ${ }^{1}$, S.V Rajeeva ${ }^{2}$ \\ ${ }^{I}$ M.Tech.(Structural Engineering), Department of Civil Engineering, SJBIT, Karnataka, India \\ ${ }^{2}$ Professor, Department of Civil Engineering, SJBIT, Karnataka, India
}

\begin{abstract}
Plan irregular structures situated in earthquake prone areas are very important issue to be taken into account. The present study deals with the horizontal irregularity - re-entrant corner. The paper focusses on the comparison of regular building and the reentrant corner buildings by conducting time history analysis located in seismic zone V. The time history analysis is carried out using the data of past BHUJ earthquake. The FE software ETABS v 9.7.4 has been used for the analysis. The evaluation and comparison of the regular and irregular buildings has been done using the parameters - storey displacement, storey drift, time period and base shear. Also the forces on the columns near the re-entrant corner has been studied.
\end{abstract}

Keywords: Horizontal irregularity, displacement, drifts, re-entrant corner, time history analysis, etc.

\section{INTRODUCTION}

Earthquake is a natural hazard that causes severe damages and losses. One of the important reasons for the failure of $\mathrm{RC}$ multi-storey structures is its irregularity in plan. In this paper, the performance of buildings with re-entrant corners is studied. Re-entrant corner is said to exist in a structure when projection of the structure beyond any corner is greater than $15 \%$ of the plan dimension in direction considered [1].

Different methods of analysis are prescribed by the IS 1893 2002, for the analysis of structures. For structures that are unsymmetrical in plan and elevation, dynamic methods such as response spectrum method and time history method are the most suitable. For the time history method, the actual accelogram records are input to the software and the analysis is performed.

As the time history method makes use of the acceleration details of earthquakes, it is mostly adopted for asymmetrical and high-rise buildings. In this study, the Bhuj earthquake accelerogram is used.

Tension forces at the edges and distributes the shear stresses over it. In order to reduce the torsional forces in the structure, the shear walls are generally provided symmetrically and along both directions of the plan of the building.

\section{LITERATURE REVIEW}

Shreyasvi.C and B.Shivakumaraswamy [2015] [2]: compared the behaviour of regular and re-entrant structures in various seismic zones. Both response spectrum method and time history method was performed using ETABS. Accelerograms of Bhuj and Elecentro earthquake was used for time history method. For the regular and irregular models, storey displacements, time periods and storey shears were compared. The drift and storey displacement were more for irregular building.

Prajapati P.B and Prof. Mayur G Vanza [2014] [3]: in this study, the comparison of seismic response between a rectangular, C shape and L shape was done. SAP 2000 software was used for the static and dynamic analysis. In case of time history method, the accelerograms of Uttarkhasi, Bhuj and Chamoli was considered. Parameters such as deflections at the joints, storey shears were compared for different models.

Arunava Das and Priyabrata Guha [2016] [4]: in this paper, behaviour of four storey irregular and regular building subjected to earthquake loads were compared. Time history analysis and pushover analysis was performed using SAP2000. Elecentro acceleration details were used for time history method. From the results, it was observed that in case of irregular model, the displacements from pushover analysis was greater than that of time history analysis.

Arvindreddy and R.J.Fernandes [2015 [5]: investigated the response of regular and plan irregular structures under zone V. Static and dynamic methods were conducted using ETABS. The displacements of both regular and irregular models were compared for the different methods and it was concluded that static method gave higher displacements compared to dynamic method.

\section{OBJECTIVES}

(i) To investigate the behaviour of re-entrant corner buildings under dynamic loading.

(ii) To compare the behaviour of $\mathrm{RC}$ regular and irregular frames in zone $\mathrm{V}$. 
(iii) To study the parameters such as displacement, drift, base shear and time period of both irregular and regular buildings.

(iv) To study the column forces for columns near the reentrant corner.

(v) To carry out time history method for both regular and irregular models.

\section{MODELLING}

The analysis of both regular and re-entrant structures (30 storeys) have been analysed for both gravity and lateral loads. ETABS v9.7.4 has been used for the modelling and to carry out the analysis. The analysis results are obtained for seismic zone V.

\subsection{Model Data}

Table 4.1 Details of building model

\begin{tabular}{|l|l|}
\hline Plan dimension & $60 \mathrm{~m} \mathrm{x} \mathrm{60m}$ \\
\hline Storey height & $3 \mathrm{~m}$ \\
\hline Bay width along X direction & $6 \mathrm{~m}$ \\
\hline Bay width along Y direction & $6 \mathrm{~m}$ \\
\hline Grade of steel & $\mathrm{Fe} 415$ \\
\hline Grade of concrete & $\mathrm{M} 30$ \\
\hline Size of beams & $300 \mathrm{~mm} \times 600 \mathrm{~mm}$ \\
\hline Size of columns & $750 \mathrm{~mm} \mathrm{x} \mathrm{750mm}$ \\
\hline Thickness of slab & $150 \mathrm{~mm}$ \\
\hline Density of concrete & $25 \mathrm{kN} / \mathrm{m}^{3}$ \\
\hline Floor finishes & $1 \mathrm{kN} / \mathrm{m}^{3}$ \\
\hline Live load & $3 \mathrm{kN} / \mathrm{m}^{3}$ \\
\hline Glazing load & $1.875 \mathrm{kN} / \mathrm{m}^{3}$ \\
\hline Thickness of shear wall & $300 \mathrm{~mm}$ \\
\hline Zone factor, Z & 0.36 \\
\hline Importance factor, I & 1 \\
\hline Response reduction factor R & 5 \\
\hline Soil type & $\mathrm{II}-\mathrm{Medium}$ \\
\hline
\end{tabular}

\subsection{Model Type}

Table 4.2 Type of models

\begin{tabular}{|l|l|}
\hline Model & Type \\
\hline 1 & RC Regular frame \\
\hline 2 & $\begin{array}{l}\text { L shape with } 60 \% \text { re-entrant along X } \\
\text { and Y directions }\end{array}$ \\
\hline 3 & $\begin{array}{l}\text { L shape with } 70 \% \text { re-entrant along X } \\
\text { directions }\end{array}$ \\
\hline 4 & $\begin{array}{l}\text { L shape with } 80 \% \text { re-entrant along X } \\
\text { directions }\end{array}$ \\
\hline
\end{tabular}


Fig. 4.1 Plan and 3D view of model 1
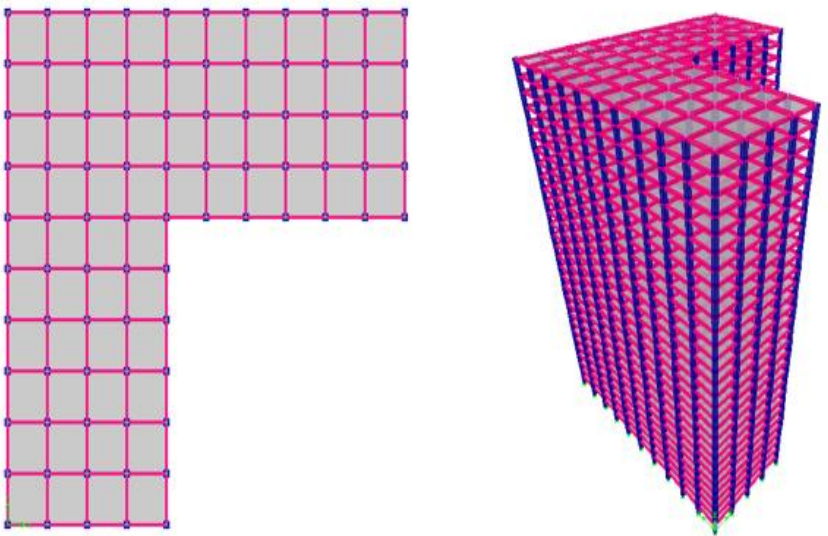

Fig. 4.2 Plan and 3D view of model 2
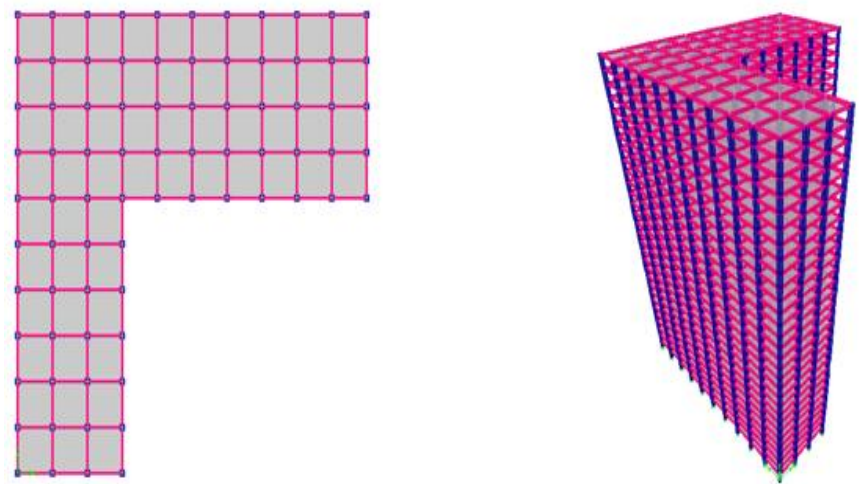

Fig. 4.3 Plan and $3 \mathrm{D}$ view of model 3
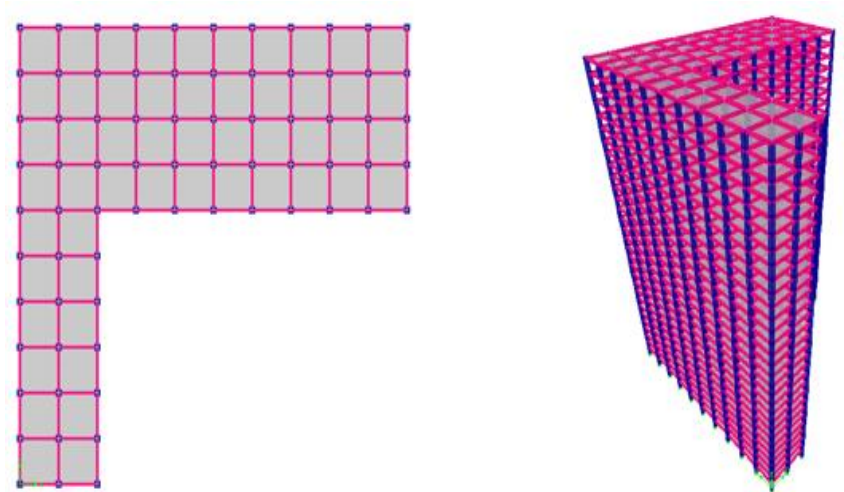

Fig. 4.4 Plan and 3D view of model 4 


\section{RESULTS AND DISCUSSIONS}

Storey displacement, storey drifts, base shear and time period values are taken from the software. The comparison between the regular and re-entrant models for the parameters mentioned above presented in tables and figures below.

\subsection{Maximum Storey Displacements}

The table and Fig below shows the maximum displacement values for the different models.

Table 5.1 Maximum displacement in $\mathrm{X}$ and $\mathrm{Y}$ direction

\begin{tabular}{|l|l|l|}
\hline Models & $\begin{array}{l}\mathrm{Ux} \\
(\mathrm{mm})\end{array}$ & $\begin{array}{l}\mathrm{Uy} \\
(\mathrm{mm})\end{array}$ \\
\hline 1 & 181.9 & 181.9 \\
\hline 2 & 183.43 & 184.84 \\
\hline 3 & 183.97 & 185.64 \\
\hline 4 & 184.34 & 186.77 \\
\hline
\end{tabular}

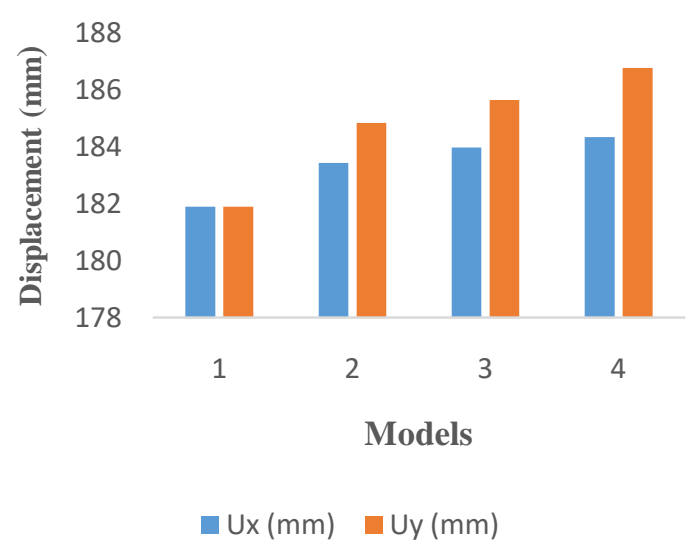

Fig. 5.1 Maximum storey displacement along $\mathrm{X}$ and $\mathrm{Y}$ direction

From table 5.1 and Fig.5.1 it can be observed that the displacements are higher along Y direction in all the models. Model 4 with $80 \%$ re-entrant is experiencing the maximum displacement whereas the displacement is minimum in the regular frame.

\subsection{Maximum Storey Drifts}

The table and Fig below shows the maximum drift ratios for the different models.

Table 5.1 Maximum drift ratio in $\mathrm{X}$ and $\mathrm{Y}$ direction

\begin{tabular}{|l|l|l|}
\hline Models & Drift X & Drift Y \\
\hline 1 & 0.0027 & 0.0027 \\
\hline 2 & 0.00282 & 0.00282 \\
\hline 3 & 0.00288 & 0.00287 \\
\hline 4 & 0.00297 & 0.00292 \\
\hline
\end{tabular}

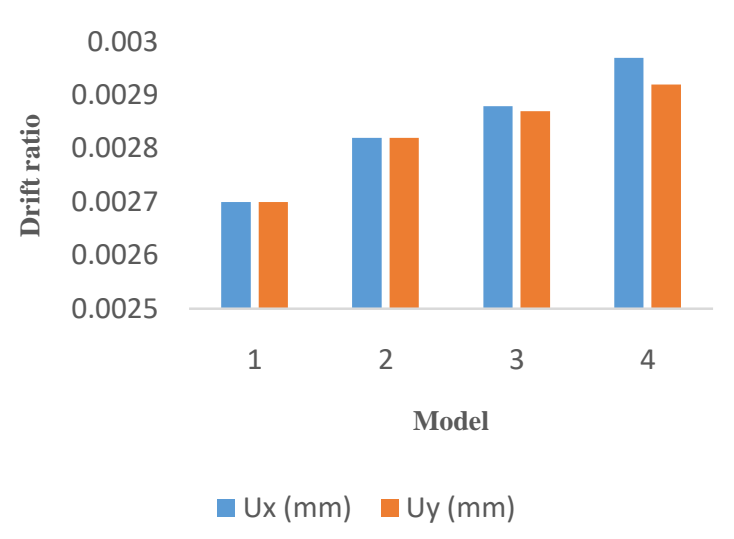

Fig. 5.2 Maximum storey drift ratios along $\mathrm{X}$ and $\mathrm{Y}$ direction

From table 5.2 and Fig.5.2 it can be observed that the drifts are same along $\mathrm{X}$ and $\mathrm{Y}$ directions for model 1and model 2. Model 4 is having the maximum drift with a drift ratio of 0.00297 amd0.00292 along X and Y directions respectively.

\subsection{Base Shear}

The table and Fig below shows the base shear values for the different models.

Table 5.3 Base shear of all the models

\begin{tabular}{|l|l|}
\hline Models & $\begin{array}{l}\text { Base shear } \\
(\mathrm{kN})\end{array}$ \\
\hline 1 & 20363.41 \\
\hline 2 & 13465.62 \\
\hline 3 & 12311.81 \\
\hline 4 & 11161.58 \\
\hline
\end{tabular}



Fig. 5.3 Base shear of all the models

From table 5.3 and Fig.5.3 it can be observed that due to lesser mass, the base shear of model 4 is minimum. The regular plan structure is having the highest base shear.

\subsection{Time Period}

The table and Fig below shows the time period for the different models. 
Table 5.4 Time period of all the models

\begin{tabular}{|l|l|}
\hline Models & Time period (s) \\
\hline 1 & 3.39 \\
\hline 2 & 3.44 \\
\hline 3 & 3.47 \\
\hline 4 & 3.51 \\
\hline
\end{tabular}



Fig. 5.4 Base shear of all models

From table 5.4 and Fig.5.4 it can be observed that the time period is maximum in $80 \%$ re-entrant building. The regular model is having the minimum vibration period under seismic loads.

\subsection{Column Forces}

The table and Fig below shows the column forces of interior and the column near the re-entrant corner for the irregular models.

Table 5.5 Column forces for all the irregular models

\begin{tabular}{|l|l|l|}
\hline Model & $\begin{array}{l}\text { Interior column } \\
\text { force }(\mathrm{kN})\end{array}$ & $\begin{array}{l}\text { Re-entrant } \\
\text { column force } \\
(\mathrm{kN})\end{array}$ \\
\hline 2 & 14665.7 & 16057.38 \\
\hline 3 & 14660.99 & 15850.31 \\
\hline 4 & 14649.9 & 15038.29 \\
\hline
\end{tabular}



Fig. 5.5 Column forces for all the irregular models

From table 5.5 and Fig. 5.5 it can be observed that the column near the re-entrant corner is subjected to greater stress and forces. Model 2 with $60 \%$ re-entrant along both X and $\mathrm{Y}$ directions is having higher column forces.

\section{CONCLUSION}

1. Re-entrant buildings undergo the maximum displacement and drift compared to the regular frame.

2. In this study building with $80 \%$ re-entrant deflects more compared to the other buildings.

3. The displacement of all the models are exceeding the maximum limit prescribed by IS 1893-2002

4. The regular models undergo the minimum storey drift compared to the irregular models. The storey drift of $80 \%$ re-entrant building is maximum.

5. The drift ratios of all the models are found to satisfy the limit prescribed by IS 1893-2002.

6. Due to lesser area and mass, the model having $80 \%$ reentrant is having the least base shear. The regular model is having higher bae shear indicating greater stiffness.

7. Irregular models are having greater values of time period and hence are less stiff compared to the regular model.

8. The stress and forces for the columns near the re-entrant corner are higher.

\section{ACKNOWLEDGEMENTS}

The authors sincerely thank former Professor and Head Prof. Prasad CSMV, Professor and Head Prof. Narendra Kumar H, Department of Civil Engineering, and Dr. Puttaraju, Principal, SJB Institute of Technology, Bengaluru for their encouragement and for providing facilities to carry out this research work as a part of $\mathrm{M}$. Tech project.

\section{REFERENCES}

[1] IS 1893 (Part 1) (2002), "Criteria for earthquake resistant design of structures", Part 1 General provisions and building, Fifth revision, Bureau of Indian standards.

[2] Shreyasvi.C, B.Shivakumaraswamy, "A Case Study on Seismic Response of Buildings with Re-Entrant Corners",IJERT, Vol 4, Issue 5, May-2015.

[3] Prajapati, P.B, Prof. Mayur G Vanza, "Influence Of Plan Irregularity On Seismic Response Of Buildings”,IJERA, Vol 4,Issue 6, June 2014.

[4] Arunava Das, Priyabrata Guha, "Comparative Study of the Static and Dynamic Seismic Analysis of RC Regular and Irregular Frame Structures", IJSER, Vol.7, Issue: 4, April-2016.

[5] Arvindreddy, R.J.Fernandes, "Seismic Analysis of RC Regular and Irregular Frame Structures", IJERT, Vol.2, Issue: 5, Aug-2015.

\section{BIOGRAPHIES}

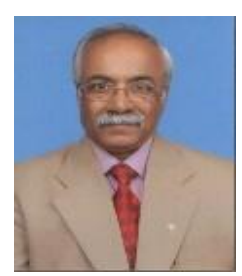

Dr. Rajeeva S V, presently working as an Engineering, SJBIT, Bengaluru. He has total teaching experience of 34 years. He obtained M. Tech from NITK, Surathkal and Ph.D. from IIT, Madras with a specialization in Structural Engineering. He has guided $46 \mathrm{M}$. Tech and $2 \mathrm{Ph} . \mathrm{D}$. thesis. He is a member of ACCE, IIBE, ICI, IE, ISET, ISTE. 
Ms. Malavika Manilal, PG Student, M. Tech,

Structural Engineering, at SJB Institute of

Technology, Bengaluru. 